\title{
Enhancement Performance of Hybrid Membrane Zeolite/PES for Produced Water Treatment With Membrane Modification Using Combination of Ulta Violet Irradiation, Composition of Zeolite and Thermal Annealing
}

\author{
Tutuk Djoko Kusworo*, Annizah Rahmatya Gerhana and Noor Hanifah Angga Putra
}

Chemical Engineering Department, Engineering Faculty, Diponegoro University, Jl. Prof. Sudharto, Tembalang, Semarang, 50239 , Indonesia Tel./Fax: +62-24-7460058

\begin{abstract}
Produced water is a wastewater from oil production that must be treated well. Membrane is one alternative of water treatments technology based on filtration method. However, in the use of membrane, there's no exact optimal variable that influences membrane performance. This underlying research to assess factors that influences membrane performance to obtain optimal condition. Therefore, the objectives of this study are determining the effect of variable process in membrane fabrication and several modification techniques on membrane performance. The membranes were fabricated via dry-wet phase inversion method. The process variables of this experiment are varying the Zeolite concentration by low level $1 \%$ weight and $3 \%$ weight, UV irradiation time low level 2 minutes and high level 6 minutes, thermal annealing temperature low level $160^{\circ} \mathrm{C}$ and high level $180^{\circ} \mathrm{C}$. The experiment runs were designed using central composite design. From the research that has been perfromed, PES/Zeolit membrane has a higher permeability after being irradiated by UV light and denser pore after heating and the longer of annealing time.
\end{abstract}

\section{Introduction}

Produced water is waste water from crude oil production process. Produced water come out with oil that going up to surface and containing much of dangerous chemicals and contaminants. Before produced water is thrown away, it should be given some treatments so that the produced water is appropriate with valid standard [1]. Produced water can be used for pulling out the oil. Beside that, in some wells, produced water used to pressure maintenance during crude oil production process [2]. The benefit of using this method is to keeps the environment clean. It can reduce the danger contaminant that can affect human, plants, and the others. There are so many pre-treatment methods that can be used like air flotation, hydrocyclone, coalescer bed, and filtration. From all of the methods above, filtration technology is the one of other alternatives that can be developed because it has many advantages [3].

Membrane is one of many water treatment technologies. Where membrane can separate chemical components specifically, can separate in low temperature, work continuously, energy saving, the process is not destructive for the separated chemical components, and didn't give negative effect for environment. Membrane is a selective obstacle between two phases. Membrane has various thickness, there is tin membrane, thick membrane, homogene membrane, and heterogene membrane. Membrane separates material based on molecule size and shape, sustain the component from feed that is having larger size than membrane pores, and release the component that is having smaller size.

In other side the uses of membrane for water treatment still have some disadvantages such as rejection decreasing along with flux increasing, and fouling. Therefore, hybrid membrane with polyether- sulfone material/Zeolit will be developed in this research. Membrane will be made with phase inversion for producing ultrathin membrane, while the combination of UV irradiation and thermal annealing are expected to make the membrane more improving against fouling and enhancing membrane performance such as flux value

Corresponding author: tdkusworo@che.undip.ac.id 
and percent rejection of membrane. The performance of the membranes include membrane permeability and selectivitity. The performance of the membrane influenced by the structure of its morphology, where the structure of a membrane that is formed is a result of the influence of several factors, including the composition of the membrane forming material and the addition of additives, the mistreatment at the grafting and treatment at the time of post treatment.

\section{Materialls and Methods}

The materials used in this research include: PES from Sigma Aldrich Chemie GmbH Steinheim Germany used as a membrane mix matrix material forming, Zeolite frome Indrasari Chemical Store Semarang, and distilled water UPT Integrated Laboratory of the University of Diponegoro. Original produced water samples from PT. Pertamina E \& P Cirebon. This study were divided into three stages. The Variable using Run from Statistica 6. Software.

Table 1. Formulation Variable Factor

\begin{tabular}{|c|c|c|c|}
\hline Run & $\mathrm{A}(\% \mathrm{wt})$ & $\mathrm{B}(\mathrm{mnt})$ & $\mathrm{C}\left({ }^{\circ} \mathrm{C}\right)$ \\
\hline 1 & 1.00 & 2.00 & 160.00 \\
\hline 2 & 1.00 & 2.00 & 180.00 \\
\hline 3 & 1.00 & 6.00 & 160.00 \\
\hline 4 & 1.00 & 6.00 & 180.00 \\
\hline 5 & 3.00 & 2.00 & 160.00 \\
\hline 6 & 3.00 & 2.00 & 180.00 \\
\hline 7 & 3.00 & 6.00 & 160.00 \\
\hline 8 & 3.00 & 6.00 & 180.00 \\
\hline 9 & 2.00 & 4.00 & 170.00 \\
\hline 10 & 0.24 & 4.00 & 170.00 \\
\hline 11 & 3.76 & 4.00 & 170.00 \\
\hline 12 & 2.00 & 0.47 & 170.00 \\
\hline 13 & 2.00 & 7.53 & 170.00 \\
\hline 14 & 2.00 & 4.00 & 152.36 \\
\hline 15 & 2.00 & 4.00 & 187.64 \\
\hline 16 & 2.00 & 4.00 & 170.00 \\
\hline & & & \\
\hline
\end{tabular}

The first step is the of production of cellulose acetate membranes, followed by optimization using RSM for membrane applications in the processing of produced water, and phase characterization. At this stage, fabrication of cellulose acetate membrane starts with making the solution a print composed by variable in Table. 1 as the solvent. Casting membranes was using phase inversion method. This method was done by casting the membrane on the glass plate using a casting knife. Furthermore, the membrane was immersed into the coagulation bath with distilled water as non-solvent for 1 hour, followed by immersion in a different coagulation bath at ambient temperature $\left(30 \pm 2^{\circ} \mathrm{C}\right)$ for 24 hours. After that the membrane application will be examined for produced water treatment. Rejection and permeate water flux measurement are conducted using dead-end separation system. The membrane effective area in the module was determined to be $12.57 \mathrm{~cm}^{2}$. Before performing the permeability test, membrane compaction is done first using distiled water for $30 \mathrm{~min}$ so the membrane polymer chains arrange themselves. After the compaction process, distiled water was replaced with produced water and maintained at $30 \pm$ $2^{\circ} \mathrm{C}$. Produced water flux determination is done by measuring the volume of produced water for every 10 min. Membrane rejection was performed by determining the concentration of $\mathrm{Cl}^{-}, \mathrm{S}^{-}$, TDS, COD , Turbidity before and after passing through the membrane barrier. Determination of TDS was performed using a TDS meter, Turbidity using Turbidimeter, the analysis of $\mathrm{Cl}^{-}$, $\mathrm{S}^{-}$, and COD ion were used titrimetric method. Figure 1 illustrated the simple process diagram of a dead-end cell apparatus for produced water separation process using prepared PES membrane. The permeate water flux was calculated by equation 1 [4]:

$$
J=\frac{V}{P \cdot A \cdot t}
$$

Where, $J=$ Flux $\left(\mathrm{L}_{\mathrm{m}} \mathrm{m}^{-2} \mathrm{bar}^{-1} \mathrm{~h}^{-1}\right), \quad V=$ permeate volume (Liter), $P=$ pressure (bar), $t=$ time (hour) $A=$ membrane effective area $\left(\mathrm{m}^{2}\right)$. Determination of the coefficient of rejection is done by analyzing the concentration of pollutants in upstream and downstream of the membrane as in the equation 2 .

$$
R=\left(1-\frac{C_{p}}{C_{f}}\right) \cdot 100 \%
$$

Where, $R$ is percent of rejection, $C_{p}$ is permeate concentration and $C_{f}$ is feed concentration [5].

\section{Result and Disscussion}

\subsection{Independent Variable Influenced towards Membrane Performance}

\subsubsection{Zeolite Concentration Influenced towards Membrane Flux}

Performance membrane PES can be seen from the flux membrane. The measurement of flux membrane performed with filtration tool for measuring the rate of alir permeat membrane per unit area per unit time. From figure 4.1 by increase time, the value of flux membrane tends to go down. It was because the longer the time of surgery, pressure through the process of filtration has been increased. Pressure has indicates fouling occurring to membrane. Fouling will increase, to cover pores 
membrane, who makes work membrane be the more severe and resulting in a reduction number of permeat. Because flux permeat is directly proportional to the volume of permeat at a particular time, so the decreasing volume of permeat resulting in flux membrane declining.This is in the overall run where flux decreased along with increase in time.

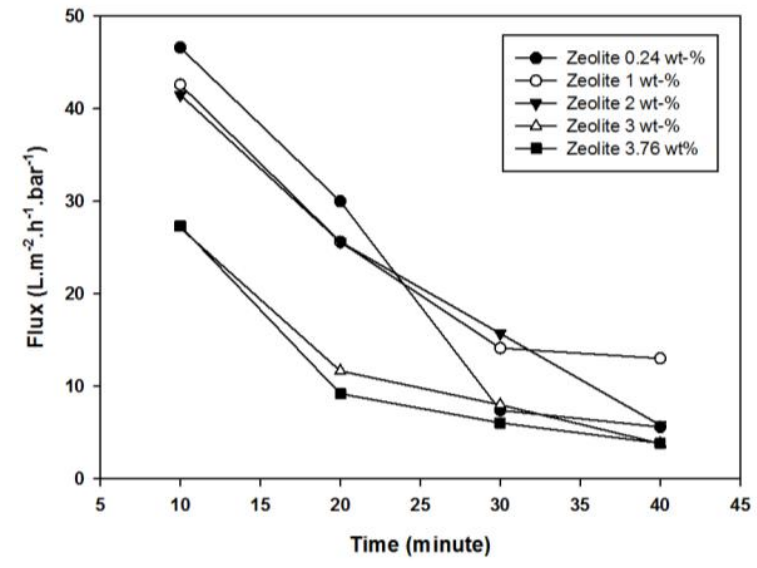

Fig. 1 The Influenced of Zeolite Concentration Toward Flux Membrane

According to Figure 1, through the increasing of zeolite concentration, the flux on membrane getting down, it was because the more the concentration of a zeolite who adds into a solution of dope will improve the ability of the permeability and transport of a substance through a zeolite. Membrane swelling will barrier by charging on material zeolite matrix membrane PES. A stable zeolite structure is not susceptible to membrane swelling in zeolite area. PES chain polymer who was in the region close zeolite, controlled by interactions among advance .Hence, zeolite particles serves as cross-linker for chains of a polymer around it .This is what causes flow of particles through a matrix membrane being obstructed that result in flux value that down if the number of zeolite the more.

\subsubsection{The Influenced of UV Ray Period towards Flux}

UV irradiation on the polymer has been studied could affect on structural changes and chemical structural reaction. The type of structural changes strongly influenced by irradiation time. The longer UV irradiation time on the membrane surface, the more complex both structural and chemical changes of the membrane surface. Membrane structure plays an important role in membrane separation performance. Therefore, the determination of optimal irradiation time is required in employing UV light to modify membrane structure. Figure 2 shows the effect of UV irradiation time on permeate fluxes in function of time.

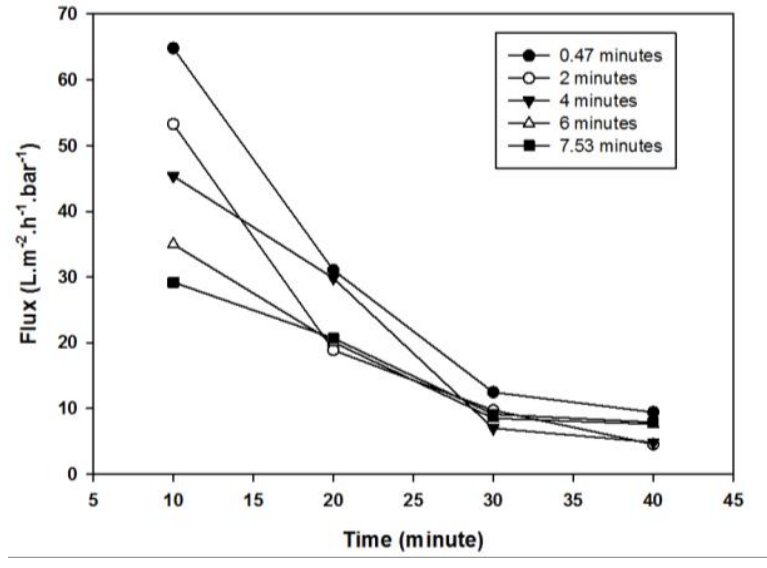

Fig. 2 Flux Membrane in different Period of UV Ray

Based on Figure 2, flux membrane that illuminated $\mathrm{UV}$ is decline. This because the delay between membrane after casting and before put in a tub coagulation ( delayed mixing ) that causes the formation of membrane non pores [6]. When solvent evaporated ,polymers solution that formed liquid move to fill pores for produce tightly pore without evaporation [7].

\subsubsection{The Influenced of Thermal Annealing towards Flux Membrane}

Polymeric membrane structure can be altered by giving a thermal treatment. the effect of annealing temperature on the permeate flux of PES/zeolite membrane is shown in Figure 3.

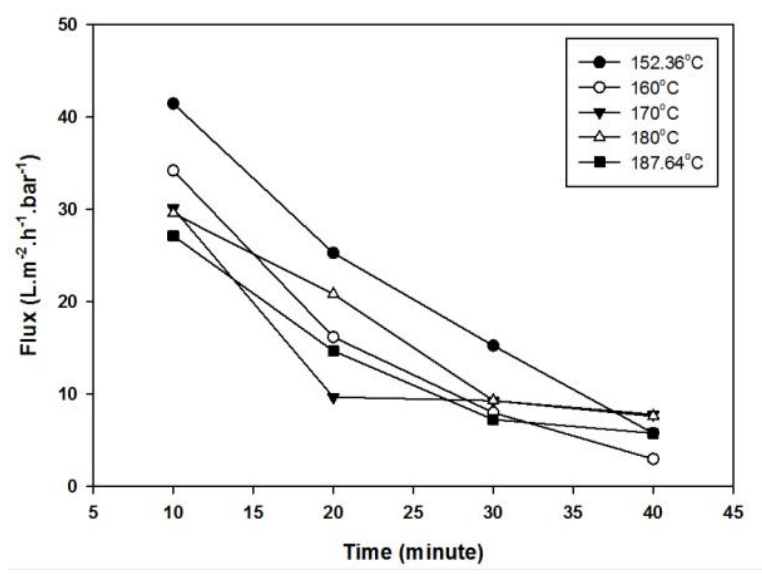

Fig. 3 Flux Membrane in different Thermal Annealing

From Figure 3 can be seen that the value of flux membrane PES by annealing lower than values flux membrane pes without annealing .Treatment annealing to membrane will cause adjustment structure chain polymers in the membrane surfaces and membranous be more stable. Pore structure in the membrane surfaces adjust equilibrium thermodynamics changed due to heat given [8]. Adjustment structure polymer chains cause the morphology change of membrane $[6,9,10]$. Flux membrane that heated at temperature $187.64^{\circ} \mathrm{C}$ lower than to the flux the membrane that is heated at temperature $152.36{ }^{\circ} \mathrm{C}$. It was because at a temperature $187.64^{\circ} \mathrm{C}$ close to transition glass polymer temperature 
PES ( $\mathrm{Tg}=220{ }^{\circ} \mathrm{C}$ ) ( Wibowo et al.,2010 ). Warming temperatures glass approaching transition to break molecules PES ties between polymer become more tightly for membrane structure that have sparse skin layer thicker. These results obtained is consistent with the previous studies [11].

Treatment warming or annealling would cause adjustment structure chain polymers in the membrane surfaces. Structure pores in the membrane surfaces adjust equilibrium thermodynamics changed due to heat given. Adjustment structure chains are causing morphological change's membrane [12]. As a result, pores formed into more stable and meetings. Pores more tightly membrane down flux obtained. The higher temperatures annealing apply to membrane, so the membrane will be more tightly so flux obtained becoming progressively lower [13].

\subsubsection{The Influenced of Zeolite Concentration towards Rejection of Ion $\mathrm{Cl}^{-}, \mathrm{S}^{2-}$, COD, TDS}

Figure 4 shows that greater concentration of Zeolite , rejection is generated. This is due to increase in the concentration of Zeolite raise viscosity of casting film and lose its diffusivity among the components in the system during the process of compacting the solution eventually cast and further hamper the process of precipitation and makes the surface of the membrane has pores smaller [14]. Thus, increasing the composition of the Zeolite will lead to a rise in the value of rejection.

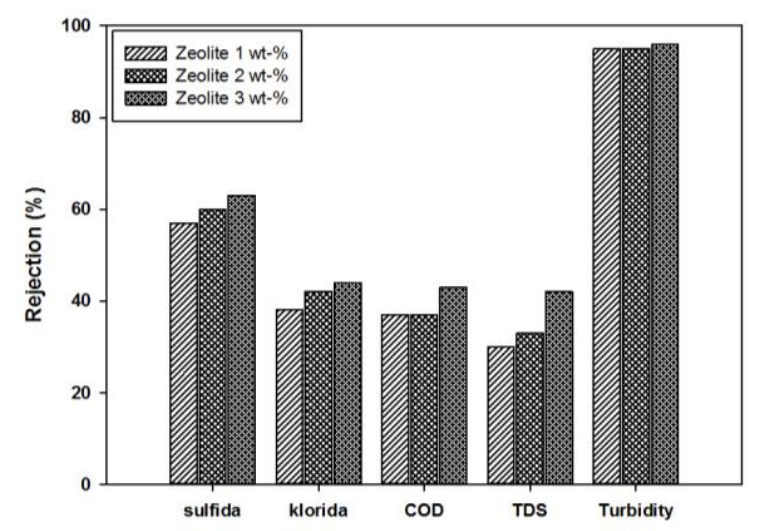

Fig. 4 Membrane rejection in different Zeolite loading and solutes

We obtained that the value of turbidity rejection is most of the influence of various zeolite concentrations. From the view of particle size, Turbidity have a particle size of $2 \mu \mathrm{m}$, the particles cause turbidity average molecular size $>5 \mu \mathrm{m}$ depending on the value of the turbidity of a liquid, ion $\mathrm{Cl}^{-}$ion has diameter of $194 \mathrm{pm}$ and ion $\mathrm{S}^{2}$-particle diameter of $145 \mathrm{pm}$. Rejection value is the value of many substances that can't passing through the pores of membrane. The rejection value of turbidity is around $95 \%$, then membranes are functional as good to hold macromolecules. While on a rejection level of ions $\mathrm{Cl}^{-}$having a level rejection at $40 \%$ and for rejection of ions $\mathrm{S}^{2-}$ as much as $65 \%$.So we can conclude that a membrane polyether sulfon with hybrid nanozeolite having the ability most either in merejeksi macromolecules in the form of ions can cause cloudiness

\subsubsection{Influenced of UV Ray Periods toward Rejection of Ion $\mathrm{Cl}^{-}, \mathrm{S}^{2-}, \mathrm{COD}, \mathrm{TDS}$}

From Figure 5 in general, show an increase of rejection value in each time filtration. Increasing number was also indicated by each rejection indicators where the longer time irradiating so performance rejection membrane is increased. Long irradiating 6 minutes produce higher rejection than the irradiating for 2 minutes and 4 minutes , the average value of $57 \%$ to Sulphide , $43 \%$ to Chloride , $42 \%$ to the COD, $33 \%$ for TDS and $98 \%$ for Turbiditas. An increasing of UV irradiating will result in part sparse layer to a membrane the back so that performance of the inner membrane of rejection is better [15]. This is further strengthened by research formerly practiced by Mansourpanah and Habili [16] where UV irradiating to prove rejection increasing in membrane to salt $\mathrm{NaCl}$ and $\mathrm{Na}_{2} \mathrm{SO}_{4}$ significantly.

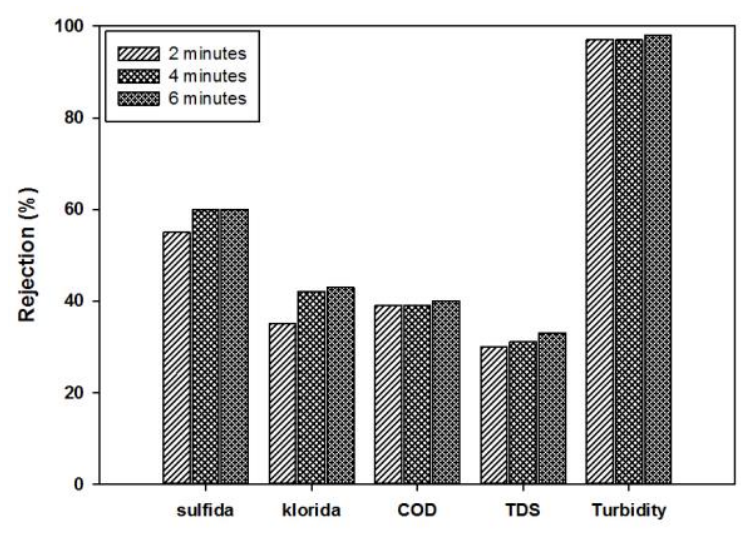

Fig. 5 Membrane rejection in different UV irradiation and solutes

In terms of rejection indicators, hybrid membrane PES-Zeolit known has all the different levels in rejected every components. It is affected by the size of every molecule who filtered out. Almost all turbidity is rejected which the figures $98 \%$ is highest than another rejection indicators. Besides it, Sulphide rejection is higher than the chloride on every long irradiating membrane. [17] claim that irradiating UV to membrane fabrication process will cause distribution membrane pores more uniform in every sections so minimize the arrival of void potential to pass molecules with a bigger size. Hence turbidity will be reduced significantly due to turbidity own the parameter cloudiness is caused by the massive particles dispersed in in the water. This also applies to sulphide, chloride and other rejection indicators . 


\subsubsection{The Influenced of Thernal Annealing towards Rejection of Ion $\mathrm{Cl}^{2}, \mathrm{~S}^{2-}, \mathrm{COD}, \mathrm{TDS}$ and Turbidity}

The effect of thermal annealing on the membrane structure are increasing the density of the membrane and alterate the polymer become more crystalline. The effect of annealing process on the solutes rejection performance is depicted in Figure 6.

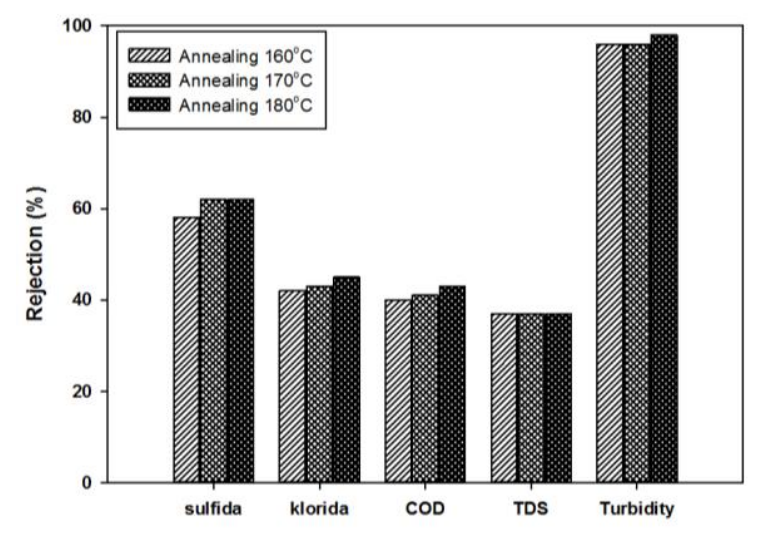

Fig. 6 Membrane rejection in different annealing temperature and solutes

Figure 6 shows the influence of temperature on thermal annealing of membrane rejection. It appears that rising temperatures will also increase the ability of membrane rejection in various components. Analogous to the previous discussion that the existence of thermal treatment on membrane fabrication will affect the structure of its morphology. Myeong and Bhattacharyya [12] reported that at the time of the thermal treatment, given membrane molecules in polymer chain will gain energy and move, so it can fix its structure. Thus the membrane polymer chains will be arranged more regularly resulting in more compact membrane layer. This is confirmed also by Bosko et al. [18] in his research using membrane $\mathrm{Pd}-\mathrm{Ag} / \mathrm{PSS}$ where annealing temperature increase would cause a uniform deposition in each segment lining membrane.

\section{Conclusions}

The hybrid membrane PES/Zeolite was successfully fabricated in this work. The modification methos seems significantly enhanced membrane performance. The increasing of zeolite concentration, the flux on membrane getting down, it was because the more the concentration of a zeolite who adds into a solution of dope will improve the ability of the permeability and transport of a substance through a zeolite. Membrane swelling will barrier by charging on material zeolite matrix membrane PES. The flux membrane that UV irradiated is decline and permeability is arised. This is because the delay between membrane after casting and before put in a tub coagulation (delayed mixing) that causes the formation of membrane non pores. Treatment annealing to membrane will cause adjustment structure chain polymers in the membrane surfaces and membranous be more stable. Pore structure in the membrane surfaces adjust equilibrium thermodynamics changed due to heat given.

\section{References}

1. F.R. Ahmadun, A. Pendashteh, L.C. Abdullah, D.R.A Biak, S.S Madaeni, Z.Z. Abidin. J. Haz. Mat., 170, 530-551. (2009).

2. A.F. Ismail, Hassan, A.R.; Ng, B.C. J. Sci. Techn. Membr. Sci. \& Tech., 24. 879-889. (2002).

3. Kaeselev, Bozena; Kingshott, Peter; Jonsson, Gunnar, Desalination, 146, 265-271. (2002).

4. B.E. Kirk, and D.F. Othmer, The Interscience Encyclopedia Inc, New York. (1996).

5. F. Macedonio, A. Ali, T. Poerio, E. El-Sayed, E. Drioli, M. Abdel-Jawad, Sep. Purif. Tech., 126, 6981. (2004).

6. M. Mulder, Kluwer Academic Publishers, Netherland. 1996.

7. H. Zhang, Zhong, W. Xing, Desalination, 309, pp. 84-90. (2013).

8. I.C. Kim, H.G. Yun, K.H. Lee, J. Membr. Sci., 199, 75-84. (2002)

9. S. Mulyati, Reintek J. Ilmu Pengetahuan Tek. Terapan 3(2), 2. (2008).

10. A.P. Siswanto, and A.D. Aufa, J. Penelitian Membran Teknik Kimia Undip. 2011.

11. T.D. Kusworo, Budiyono, J. Supriyadi, D.C> Hakika. Intern. J. Waste Res. 4(1), 1-9. (2014).

12. Myeong, Jin-han, and Bhattacharyya, D., Desalination, 101, 195-200. (1994).

13. T.D. Kusworo, A.F. Ismail, Budiyono, World Appl. Sci., 28(1), pp. 9-19. (2013).

14. A. Motta, C. Borges, K. Esquerre, A. Kiperstok, J. Membr. Sci., 469, 371-378. (2014).

15. P.A. Nur, D.K. Sari, H. Susanto, J. Tek. Kim. Ind., 2, 189-197. (2013).

16. Y. Mansourpanah, and E.M. Habili,. J. membr. sci., 430, 158-166. (2013)

17. M. Sangermano, A. Chiolerio, G.P. Veronese, L. Ortolani, R. Rizzoli, F. Mancarella, and V. Morandi. Macromol. Rap. Comm., 35(3), 355-359. (2014).

18. M.L. Bosko, J.B. Miller, E.A. Lombardo, A.J. Gellman, and L.M. Cornaglia. J. Membr. Sci., 369(1), 267-276. (2011). 